\title{
Tobia Zanon, Traduzioni settecentesche del teatro tragico francese
}

\section{Franco Piva}

\section{Q OpenEdition}

1 Journals

\section{Edizione digitale}

URL: http://journals.openedition.org/studifrancesi/9209

DOI: 10.4000/studifrancesi.9209

ISSN: 2421-5856

\section{Editore}

Rosenberg \& Sellier

\section{Edizione cartacea}

Data di pubblicazione: 1 juin 2008

Paginazione: 185

ISSN: 0039-2944

\section{Notizia bibliografica digitale}

Franco Piva, «Tobia Zanon, Traduzioni settecentesche del teatro tragico francese», Studi Francesi [Online], 154 (LII | I) | 2008, online dal 30 novembre 2015, consultato il 08 janvier 2021. URL: http:// journals.openedition.org/studifrancesi/9209; DOI: https://doi.org/10.4000/studifrancesi.9209

Questo documento è stato generato automaticamente il 8 janvier 2021.

\section{(c) (i) (9)}

Studi Francesi è distribuita con Licenza Creative Commons Attribuzione - Non commerciale - Non opere derivate 4.0 Internazionale. 


\title{
Tobia Zanon, Traduzioni settecentesche del teatro tragico francese
}

\author{
Franco Piva
}

\section{NOTIZIA}

TOBIA ZANON, Traduzioni settecentesche del teatro tragico francese, «Stilistica e metrica italiana», 5 (2005), pp. 95-140 e 6 (2006), pp. 123-156.

1 Il Settecento fu il secolo che vide, con ogni probablità, la più intensa attività di traduzione dal francese all'italiano. La cosa si spiega facilmente: la Francia rappresentava allora l'apice riconosciuto della civiltà europea; il suo prestigio era immenso; ad essa guardavano tutti con ammirazione, sia per quanto essa stava producendo in quello stesso periodo di riflessione sull'uomo, sulla società e sul mondo, sia per quanto essa era riuscita a produrre, nel secolo precedente, nell'ambito soprattutto del teatro. Corneille e Racine avevano del resto trovato, almeno agli occhi dei contemporanei, dei degni eredi in Crébillon e in Voltaire, per non citare che gli autori più osannati. Al teatro tragico francese guardavano con ammirata attenzione tutti i letterati europei; tra essi anche gli italiani che quel teatro cercarono di appropriarsi, prima di tutto attraverso l'esercizio della traduzione. Un esercizio che sollecitò molti all'epoca e per le più diverse ragioni: da quelle più bassamente commerciali (offrire nuovi titoli al repertorio dei vari teatri, pubblici e privati), a quelli più nobilmente letterari: cercare di far passare nella tradizione italiana il meglio del grande teatro, soprattutto tragico, d'oltralpe. Tobia Zanon evoca le oltre 300 versioni di pièces francesi individuate, negli anni Venti del secolo scorso, da Luigi Ferrari; un numero impressionante che le indagini svolte successivamente hanno tuttavia aumentato di parecchio, e che altre e più puntuali indagini incrementerebbero ulteriormente. 
2 Al di là dell'ampiezza del fenomeno, che testimonia dell'importanza e della capillarità di una influenza che all'epoca interessò, per la verità, anche altri ambiti, il problema più interessante era capire come questi traduttori abbiano reso il testo francese. Certo, la lingua francese era una lingua sorella dell'italiana, quindi tutto sommato facile da tradurre. Il problema si complicava però perché nella maggior parte dei casi, si trattava di pièces in versi. Se una parte non indifferente preferì ricorrere alla soluzione, certamente più facile, della prosa, la maggioranza dei traduttori, in particolare quelli più noti ed esigenti, cercarono di rendere il teatro francese in versi, come esso era nell'originale. Questa scelta, encomiabile, pose ai traduttori tutta una serie di problemi, di carattere metrico, stilistico e sintattico che l'autore esamina sulla base di un corpus bene definito, con grande attenzione ed acribia.

Il primo problema nasceva dal fatto che la letteratura italiana non possedeva un metro corrispondente dell'alessandrino francese che, come è noto, comportava anche un ben preciso gioco di rime. Nella maggior parte dei casi si ricorse all'endecasillabo sciolto, con una soluzione apparentemente molto lontana da quella adottata dai tragici francesi, ma che si inseriva bene e traeva per altro verso la sua origine dalla tradizione italiana; e con esiti a volte alquanto diversi; si tentarono anche altre soluzioni, come il verso martelliano o l'alternanza endecasillabo/settenario, che tuttavia non riuscirono ad imporsi. Grande importanza assunsero, in ogni caso, il ritmo e la posizione rispettiva delle varie parti del discorso, che Zanon esamina anche con molta attenzione in una parte ulteriore del suo studio, al punto che la cifra peculiare dei diversi traduttori sembra passare proprio attraverso queste soluzioni ritmico-stilistiche, le quali hanno, come è ovvio, una grande attinenza da un lato con la sintassi, dall'altro con lo stile o con la retorica, aspetti che Zanon affronta nell'ultina parte del suo interessante lavoro.

Per i letterati del Settecento italiano la traduzione del teatro tragico francese fu quindi un esercizio molto complesso ed impegnativo, destinato a risolversi, nel migliore dei casi, in un compromesso fra due tradizioni apparentemente vicine, di fatto molto distanti, di cui Zanon presenta bene i termini, ed in qualche modo anche le prospettive: «La mancanza della rima e la preponderante funzione organizzativa dell'enjambement per i testi in endecasillabi sciolti, la differente miscela verbale per i testi in forme libere di endecasillabi e settenari, la rigida struttura del distico martelliano, tutti questi elementi - ricorda Zanon - impongono al poeta-traduttore settecentesco un più generale ripensamento del verso in un equilibrio continuamente funanbolico tra le proposte di rinnovamento derivanti dal modello francese e le tradizionali esigenze del codice letterario italiano». 